Development of a Case Formulation Model for Individuals who have Viewed, Distributed and/or Shared Child Sexual Exploitation Material

Hannah L. Merdian ${ }^{1}$, Derek E. Perkins ${ }^{2}$, Elspeth Dustagheer ${ }^{3}$, \& Emily Glorney ${ }^{2}$

${ }^{1}$ University of Lincoln, ${ }^{2}$ Royal Holloway, University of London, and ${ }^{3}$ University of Surrey

Published in the International Journal of Offender Therapy and Comparative Criminology.

Doi: $10.1177 / 0306624 X 17748067$ 


\begin{abstract}
Increases in the number of arrests of individuals who download or distribute Child Sexual Exploitation Material (CSEM) have highlighted a need to further understand the offending pathways of this offender group. This article describes the development of an aetiological model specific to CSEM offending. Individuals who had viewed, distributed and/or shared $\operatorname{CSEM}(n=20)$ were interviewed regarding their life and sexual history, relationships, substance use, offending details, and circumstances leading to their CSEM offending, resulting in seven superordinate themes: Developmental Context, Individual Propensities (risk-related and risk-protective) and Psychological Vulnerabilities, Personal Circumstances, Permission-Giving Thoughts, Internet Environment and Behaviour, Evaluation of Consequences for the Individual, and Desistance. These themes were combined into a case formulation tool specific for CSEM offending behaviour, with the aim of providing systematic guidance for assessment and treatment providers.
\end{abstract}

Keywords: child sexual exploitation, child sexual abuse, illegal images of children, risk management, case formulation 


\section{Development of a Case Formulation Model for Individuals who have Viewed, Distributed and/or Shared Child Sexual Exploitation Material}

Child Sexual Exploitation Material (CSEM) is the term used for any type of material depicting the sexual exploitation of children, such as indecent photographs of children (UK) or child pornography (Canada), but can also refer to material not always included in legal classifications, such as abuse-related narratives, audio files, or exploitative chat room conversations.

In the last decade, there has been an increased number of arrests and convictions for online CSEM offences (Crown Prosecution Service, 2014), certainly also linked to advances in detection of online offending behaviour. Due to its accessibility, affordability, and anonymity (so-called Triple-A-Engine; Cooper, 1998), the Internet provides a unique environment (and often lack of supervision) within which to commit online offences (Seto, 2013; Wortley \& Smallbone, 2006).

The empirical evidence suggests that individuals who have committed CSEM offences more likely present with deviant sexual interests than individuals who were convicted for a contact sex offence; however, they are also likely to have lifestyle and psychological barriers to contact offending (i.e., low victim access; greater victim empathy; or less antisociality) inhibiting them from acting on deviant interests, and were also found to be less likely to have access to children (Babchishin, Hanson, \& VanZuylen, 2015; Seto, 2013; Seto, Cantor, \& Blanchard, 2006; Webb, Craissati \& Keen, 2007). The existing research further suggests that, whilst for some individuals, their CSEM offending is linked to a sexual interest in children that may translate into offline spaces (i.e., contact-driven offenders), there appears to be a distinct group who view CSEM seemingly without intent to commit a contact offence (fantasy-driven offenders; Merdian et al., 2016). Given that CSEM 
offenders in general, but fantasy-driven offenders in particular, display personal and offencerelated characteristics distinguishing their treatment needs from those of contact sex offenders (Babchishin et al., 2015), existing theoretical and aetiological models of contact sex offending have been found to make a limited contribution to explain the aetiology and maintenance of CSEM offending (e.g. Middleton, Elliot, Mandeville-Norden, \& Beech, 2006). Further, existing risk and treatment need frameworks for contact sex offenders have been shown to lack specificity for CSEM offenders (e.g., Middleton, Mandeville-Norden, \& Hayes, 2009; Wakeling, Howard, \& Barnett, 2011).

Consequently, different assessment and management strategies specifically developed for this offender group need to be explored (Merdian et al., 2016; Seto, Reeves, \& Jung, 2010). Seto and Eke (2015) developed the first actuarial risk assessment tool specific to CSEM offenders, the Child Pornography Offender Risk Tool (CPORT). However, while the CPORT significantly predicted reoffending behaviour for CSEM offenders with an existing criminal history (both sexual and non-sexual), it was not predictive for non-contact CSEM offenders without such a criminal history. Thus, until new tools like the CPORT have been further validated, structured professional judgement approaches, which enable consideration of empirically derived risk factors applied to the individual's specific psychological and situational contexts, are likely to most appropriately address the nature of CSEM offending (e.g., Glasgow, 2010) and the variability in its offending patterns (e.g., contact- or fantasydriven offence motivations). In structured professional judgement assessments, empirically derived risk variables for a class of offenders are considered in tandem with individualised risk factors, but without providing probabilistic risk estimations (Mercado \& Ogloff, 2007). Even though more time consuming, this approach aims to improve risk management by focusing on individualised risk, needs, and protective factors. There are some structured professional judgement tools available for the assessment of contact sex offenders, such as 
the Sexual Violence Risk-20 (Boer, Hart, Kropp, \& Webster, 1997), but they have not been utilised for CSEM offenders.

Thus, in the absence of formal guidance on risk assessment, case formulation and treatment planning, the current study aimed to develop an aetiological and offence formulation model specific to CSEM offending, in order to enhance the conceptual understanding of CSEM offending and offer guidance to professionals working with this population. The resulting tool is therefore not an actuarial risk assessment tool (and thus not able to differentiate between CSEM offenders at high and low risk of reoffending or offence escalation) but an aid for systematic and comprehensive case formulation of the individual's risks and needs.

\section{Model Development}

\section{Design}

The model was developed in five stages: (1) Literature review, (2) Thematic analysis of 20 case interviews: Identification of emerging themes in participants' life stories that led to their CSEM offending behaviour, (3) Professional consultations on the emerging model, (4) Case validation, and (5) Information synthesis and model development. The first three stages informed the development of a theoretical framework, leading to an interim model that formed the basis of the subsequent stages. As the focus of this paper is the final case formulation tool resulting from Stage 5, only a summary of the development stages will be presented here.

\section{Overview of Stages 1-3: Theoretical Framework and Interim Model}

Theoretical Background. A comprehensive literature review identified potential markers in the aetiology of CSEM offending, including problematic early experiences, relationships and sexual histories, which in turn would influence details of the CSEM offending behaviour, and the circumstances precipitating and maintaining it. A series of 
consultations about the development process, content of the model, and selection of suitable assessment tools were conducted with professionals across forensic/ clinical practice and academia. $^{\mathrm{i}}$

The literature review and professional consultations highlighted four theoretical approaches that provided guidance in the analysis and development process. First, the Risk, Need, and Responsivity principles (RNR; Andrews, Bonta, \& Hoge, 1990) posit that the level of treatment should be matched to the risk level of the offender, should identify, assess and target criminogenic needs, and should be presented in a way that corresponds with the ability and learning style of the individual client. The RNR principles thus highlighted the need to develop a CSEM-specific case formulation tool that (1) informs about idiosyncratic risks and needs, (2) helps to target treatment in line with the identified issues, and (3) may contribute to the systematic exploration of group-based variables predictive of reoffending.

Second, the Transtheoretical Model of Change (TTM; see Prochaska \& Norcross, 2007) predicts that behavioural change is dependent on a seven-stage process that moves the client from a motivational position to a position of action (i.e., Pre-contemplation, Contemplation, Preparation Stage, Action, Maintenance, Coping with Relapse, and Termination). The TTM framework thus highlighted the need for the tool to be responsive to each stage of this process, by aiding the individual in their understanding of their own offending behaviour (and their perceived control thereof), thus supporting the individual's psychoeducation as well as active desistance planning.

Third, although developed to explain contact child sex offending, the Four PreConditions of Abuse (Finkelhor, 1984) provides a valuable and extensively adopted overview of the interplay of individual variables (motivation and internal inhibitions) and environmental variables (external inhibitions and victim factors) in the abusive behaviour. This model emphasised the role of self-management of sexually deviant interest (see also 
Babchishin et al., 2015), and the need to consider the broader situational context of the individual (see also Glasgow, 2010; Mann, Hanson \& Thornton, 2010).

Finally, Seto (2013) explored the cross-over behaviour from CSEM offending to contact sex offending. The Motivation-Facilitation Model (M-F Model; Seto, 2013) postulates that contact sex offending is dependent on a sexual interest in children (i.e., motivation), combined with offence-facilitative factors related to the individual (e.g., low psychological barriers to offending behaviour) and the situation (e.g., access to children). Again, this model points to need to consider both individual and situational factors as potential treatment targets, and to distinguish between motivational and offence-facilitative factors.

Interview Research. Based on the identified information, a semi-structured interview protocol was designed. The study drew on a development sample of 20 male participants, recruited through community-based service providers they accessed to address their CSEM offending behaviour. For all but one participant, this was their first arrest for a CSEM-related charge (legally defined as possession, distribution, and/or production of indecent image material of children). None of the participants had a conviction for a contact sex offence against a child. All participants acknowledged their offending behaviour and were at the time of data collection either attending, or had completed, group treatment, either within a probation treatment service (PT) or a voluntary treatment service (VT). Participant ages ranged between 24 and 68 years $(M=44.8$ years; $S D=13.49)$. All were of White British ethnicity. Participants were interviewed individually, either by the second or first author (or both) or by another member of the research team, supervised by the first and/or second author. With the exception of one research team member who worked for the PT at the time of data collection, none of the interviewers were related to either service providers; all PT participants were briefed on this potential conflict of interest and were able to choose their 
interview team. The individual interview sessions lasted between three and four hours. The study held ethical approval from the academic lead institution.

Interim Model. Based on these first three stages, an interim aetiological model of pathways to CSEM offending (Figure 1) was developed. This model proposed how offenders' 'offence-related vulnerabilities' (stemming from childhood and adolescent experiences, including offence-related paraphilias, maladaptive coping styles and socio-emotional loneliness) interacted with their immediate circumstances in the lead up to their offending. The model also outlined how these offence-related vulnerabilities and 'personal circumstances' interact with the 'Internet environment'. Finally, this model included consideration of the longer-term consequences of CSEM offending for the individual which, in turn, was proposed to exacerbate offence-related vulnerabilities (e.g., reinforced sexual fantasies or amplified sense of emotional loneliness) and hence negatively impact upon personal circumstances (e.g., impaired relationship or loss of employment), providing positive or negative reinforcement for future offending behaviour.

[Insert Figure 1 about here]

\section{Case Analysis (Stage 4)}

Method. The initially identified themes were internally validated on the development sample, in that cases for detailed theme analysis were randomly selected from the sample until data saturation was reached. This process resulted in the inclusion of interview protocols of 12 participants (age range: $29-68$ years; $n=6$ from the voluntary treatment programme, VT; and $n=6$ from the community probation treatment programme, PT), which were analysed using Thematic Analysis (Braun \& Clarke, 2006). An essentialist/realist and semantic approach to coding/theme development was adopted, where themes are identified through the surface meaning of the data. This inductive analysis involved the interpretation of data with regards to their broader meanings and implications for the aetiological pathways to 
CSEM offending. Transcripts were analysed by the third author and reviewed by the fourth author. Codes and themes were generated by the third author and cross-validated by the first and fourth author; any disagreement was discussed until agreement was reached.

Results. The thematic analysis identified seven superordinate themes that are, in combination, proposed to shape an individual's pathway to CSEM offending. Themes are discussed in turn briefly, with reference to illustrative quotes.

The Developmental Context. This theme refers to key learning experiences from childhood and adolescence that the participants, through the Socratic interview process, considered as distal factors contributing to their offending behaviour. Overall, the participants reported a lack of connectedness, both emotionally and physically, resulting in prolonged unmet sexual and emotional needs. Two main subthemes underpinned the participants' life stories.

The first describes a lack of connection with others and a vulnerability to socioemotional breakdown, which was represented by negative, or the absence of positive, emotional relationships together with adverse events experienced with family and peers: "My connection with my family has never been... was never great" (PT2); "I was not a particularly social person and I found it difficult to make friends" (VT6). As a result of not feeling close to others, or being rejected or overlooked by others, participants often reported spending a lot of time on their own: "I had a lot of free time... I was just kind of sitting around watching TV or playing computer games" (VT2). It emerged that these participants experienced loneliness (physical and emotional) throughout their childhood and adolescence. Moreover, the inability to connect with others appeared to have remained with them throughout their lifespan, "Even now I don't have a close community of friends" (VT1), and also impacted on their intimate and sexual relationships. 
The second subtheme refers to the role of sexual needs within and separate from (and sometimes antithetical to) intimate relationships, linked to the early experience of sex and relationships. Emotional closeness to others was often sought through intimate relationships as adults but was influenced by earlier negative experiences, such as one's own sexual abuse victimization or coercive relationships with adults during mid-adolescence: "This bloke started talking to me... we ended up in the same bed that night... he hadn't sought my consent" (VT6). There were some reports of early exposure to, and regular use of, (legal) adult pornography: "[aged 11-16] just pictures of sex... I would say an hour and a half for sex every day... it got more graphic” (PT2). Pornography consumption was further reinforced by other circumstances, such as experiencing loneliness (e.g., "It became a bad habit really, just having time on my own really"; VT2) or when feeling low (e.g., "I started to develop from quite an early age [aged 14-15] in terms of masturbation and the way it made me feel and if I'm feeling flat, that's an immediate okay quick-fix"; VT2). This seemed to introduce the notion that pornography can be used as a coping mechanism, particularly if there is a lack of connection to others. It also emerged that early exposure to pornography may have desensitised the individual to sexualised imagery.

Individual Propensities and Psychological Vulnerabilities. This theme refers to the main motivational and facilitative psychological vulnerabilities that the participants thought were directly linked to their CSEM offending behaviour. For the participants, this resulted from their Developmental Context: "I behave [this way] because of the way I was brought up" (VT5). Three subthemes were found underpin this theme: negative internal states, dysfunctional coping strategies, and a sexual interest in children.

Negative internal states represented intrinsic motivations of the participants. Many participants reported negative childhood experiences that left them with low self-esteem ("I kind of always thought that when people get to know me they won't like me", VT2), a sense 
of the self as failure ("I thought I was a failure... I'd got a family of my own but for some reason I thought I had made it go wrong because she [wife] was abusive”, PT6) and feelings of perceived worthlessness“(I was treated like scum [by father]. I just felt I wasn't worth anything”, PT1). These experiences created a negative self-bias (“[I] literally had no friends... that's when the offending started... I was so ashamed of being lonely and isolated", VT2), and contributed to increased reclusiveness, lack of connection to others, and offencerelated coping strategies. Participants spoke of feelings of emotional loneliness prior to their Internet use and subsequent CSEM offending: "I had no one to connect with... my Internet use tripled... to begin with it was gay dating sites, so making connections... then it would be pornography" (PT2). Some participants also experienced a heightened need for sex before they began offending, "We used to have sex once or twice a week, me and my wife, but you still feel sexed [sic] up where your libido wants to do something” (VT4).

Dysfunctional coping referred to strategies employed by the participants when faced with negative circumstances and subsequent negative feelings. It is likely that minimal connections during childhood and their social avoidance influenced participants' inability to talk to others about their experiences: "All I can remember at the time is just discomfort and the need to isolate as a solution to it rather than talk to people" (VT5). Participants felt that their problems “were mine and solely mine... I wouldn't communicate with people" (VT5). Participants - particularly those who were exposed to pornography at an early age - spoke of using sex to cope with life stressors, such as increased work pressure and relationship difficulties. Continued use of adult pornography caused some participants to feel that they had become desensitized (a sense of "fatigue"; VT6) whenever they were exposed to adult pornography. CSEM was experienced as "a bit different" (VT2), an effective distractor from negative emotions: "My quick-fix around things that are generally making me feel sad or the life events that have happened is to absorb myself in something... I'm not worrying about 
other stuff” (VT5). Others reported oppositional thinking and behaviour as a coping

mechanism: "Part of it is me being a good boy, so to speak, when I was younger... if you can do something wrong by yourself, 'ooooh yeah, I'm doing it” (VT4). Thus, for some participants, dysfunctional coping represented an offence-related vulnerability.

A notable feature of the participants in this study was that they were either at the end of treatment or had voluntarily opted into treatment. Perhaps linked to this, they were very open about their sexual interest in children: "I was still attracted to teenage boys" (PT6). For some participants, their own childhood sexual experiences had been perceived as positive, and thus perpetuated their sexual interest: "I think it's the psychological connection of looking at the images that I looked at to a happy time... 11-15 is the sort of age I would be interested in" (PT2).

The Internet Environment and Behaviour. This theme referred to the role of the individual's online environment as a situational facilitator of the offending behaviour. Two subthemes underpin this theme. The nature of the Internet rendered participants to experience a "...whole new world" (VT1) that seemed separate from their normal life and enabled to become a different person when online: "I feel like I'm looking at someone else talking about this" (VT5) and "it's not until you come out and look back that you start realising, 'oh my god"” (VT1). There was reference to the Internet-world being like a "bubble" (VT1; VT4) and the perception that, whilst in this bubble, the external world did not exist: "It sort of blocks out your feeling for actual living individuals... it's a kind of reality-free zone" (VT3). There were reports of detachment from the real-world whilst inside this bubble and that behaviour exhibited online would not be transferred to the real-world;

In the real world... if I saw a girl on the street and I can see the way they act and I can see they are children and they're a bit annoying... on the Internet and they're posing and stuff then in my mind... that's something I like looking at. (VT2) 
The second subtheme refers to significant online behaviours, or their psychological meanings, such as searching for CSEM material and chatting/ sharing with other CSEM offenders. Some participants with existing sexual interests in children described actively seeking CSEM. Others described being drawn to it from searches for other sexual content: "I never at one point went online specifically to look at underage images" (VT1). Nevertheless, following initial exposure to CSEM, participants reported engaging in the continuous viewing and downloading of material: "When my days were empty, because I wasn't successful with work and that, it was what I filled my days with, like trawling" (VT6). In the same way that the participants reported they had become desensitized to adult pornography, this desensitization was also reported concerning CSEM: “I wasn’t as repulsed... I became acclimatised" (PT3). This is also reflected in their downloading behaviour, "My downloading habits were getting more and more dangerous... as I downloaded more and more stuff it was-it became less of a shock" (PT3). Some participants did not save images, for fear of being caught, but participants who saved images did so to contribute to their fantasies, "I built up this fantasy world and these were - the ones that I would save contributed towards that" (VT1).

Some participants used adult and CSEM chatrooms as a means of acquiring social connections, “... a very key element of my offending... is not so much or not primarily or not exclusively the viewing of images, but the whole activity known as chat" (VT3), whereby, "I'd get what they [other CSEM offenders] recommended because the more you have, the more people - the more connections you get and the more chats you can have" (PT2). This indicates that the psychological function of the Internet environment and online behaviour is crucial in the contextualisation of CSEM offending behaviour.

Personal Circumstances. This theme referred to the individual's circumstances directly preceding their initial CSEM offending behaviour. It is evident that an individual's 
interpretation and response to these proximal factors will be influenced by their distal factors (The Developmental Context and subsequent Individual Propensities and Psychological Vulnerabilities), as well as being facilitated through the specific situational factors within their life at that time. Reference was made to a lack of connection with others, ("I had no one to connect with... 8 miles in the middle of nowhere with no one to talk to and nothing to do", PT2) and lack of sex (sex had "been on a decreasing curve", VT3), which was sometimes part of a cycle of relationship detachment: Relationship breakdown ("It was like treading on eggshells... big arguments and misunderstanding... I'd stopped caring. My empathy was bugger all”, PT3) fed into increased CSEM offending behaviour, again leading to reduced sexual activity/ emotional connection ("It became less intimate... made me feel physically unattractive"; PT3). Some participants perceived their lives to be "going downhill” (PT6): "I felt like I had failed and there was no light for me ever [following loss of employment]" (PT1). The negative situation was further enhanced by participants' dysfunctional coping strategies: "I turned to drink. That was a way to cope with the pressure" (PT2), "every night before I went to sleep I would be using pornography on the Internet. That started as a result of being less sexual within that relationship" (VT5).

Permission-Giving Thoughts. This theme referred to cognitions ("things I was doing to convince myself"; VT1) that reduced inhibitions towards CSEM offending (e.g., as offence justification), and were perceived as reinforcers for continued CSEM offending behaviour. The perception of not doing any harm helped participants to convince themselves that their behaviour was no cause for concern. There were clear references to minimisation, denial and cognitive dissonance; "It's not really hurting anyone... I've come across them on a file sharing website where someone has just uploaded them for free, I'm not causing supply or demand" (PT3); “I couldn't see what I was doing [was] wrong... I didn't see that I was hurting anybody as it was just me and a computer... I was convincing myself it was okay" 
(PT6); "I'm not as bad as [people who share images] because I'm not part of the property as it's already there... no one is getting hurt with what I'm doing" (VT2). These ideas were reinforced by beliefs that the images of children were fabricated and contributed to continued offending behaviour, the images/children are not real: "The ones on the screen weren't real people" (PT2); “The image had been created. It's not a photographer taking a picture of a child" (VT5). This perception of children was clearly linked to the perception of the Internet environment, "They're kids [in real life] but when I was on the Internet I never really put the two and two together... it just felt like an image" (VT2) and the perceived anonymity of their online behaviours: "I felt that I was sort of involved in a secret world" (VT3).

The Consequences for the Individual. This theme represented participants' experiences following their offending behaviour, in response to their (negative) perception of and inability to cope with their personal circumstances. Participants described the negative consequences of their CSEM offending, for example, some participants experienced a loss of control as a consequence of their offending behaviour, "I was becoming more disorganised... I'd become dishevelled... I started losing time" (PT3); "It caused me to be late for work... you'd go into this oblivion where time just disappeared" (VT1); or "It's a kind of mental addiction" (VT3). Some participants continued with their behaviour even though they acknowledged that what they were doing was wrong, "I deleted the whole collection, I changed my passwords... but then I went and registered another account" (PT2); "I always felt guilty afterwards... I did feel quite low a lot of the time... using indecent images definitely contributed to the way I felt when I didn't actually blank it out” (VT2). However, CSEM offending was also functional to some participants. It was described as both a negative reinforcer of the offence cycle: "I felt better within myself because I managed to calm myself down a little bit with the stress of work and family" (PT6), "it is an escape from everyday reality" (VT3), "because I became so numb and everything, it was the only way of getting a 
response out of myself" (PT3); as well as a positive reinforcer: ("it was the act of doing something illegal that was most exciting, I think"( PT2), "it was just there and use it for sexual gratification and masturbating" (PT2), "the more [images] you have... the more connections you get and the more chat you can have... it was a feeling of importance on my part" (PT2). However, while the offending behaviour initially often improved negative internal states ("I felt bad from what I was doing but then I did get some kind of pleasure out of it, and normally the good side of things would rule over the bad side of things"; VT2), the continued offending had a detrimental impact on personal circumstances: "My sole purpose was just going online... I had no interest in interaction with my wife or my kids" (VT1), or resulted in isolation, "I started retreating... into my PC" (PT3). These experiences then created, or reinforced existing, permission-giving thoughts as a way to justify continued offending behaviour, and/or avoidance behaviour, "I didn't think about it because I knew it was wrong... I'd dwell on it too much and then I'd start sinking down" (PT6); "I think that's how I kind of dealt with my offending over the years... just kind of blanked it out" (VT2).

Desistance. This final theme related to factors linked to desistance behaviours in that they that did, or could have, interrupted the offending behaviour prior to the participants' arrest. Two subthemes emerged. On a personal level, participants thought that having social contacts and increased social engagement improved their negative personal circumstances. One participants reported that his offending behaviour stopped because: "I started going out more and socialising more... having a bit more confidence in myself... I became more social and I was rarely doing things at home" (VT2). Participants highlighted that more positive social connections would have counteracted their dysfunctional coping mechanisms. As PT2 said: "If I'd have moved home to my parents, the social aspect would have changed... I have school friends there, I had friends, my brother, my older brother". And P3 stated, "if you've 
got more of a distraction then you're not as focussed on them [CSEM images]", highlighting the importance of meaningful activities in improving personal circumstances.

Participants also spoke about their concerns surrounding the accessing of external support, such as a desire for confidential help and education: "If there was some sort of support that you could speak to confidentially then yeah, I'd have probably gone down that path" (PT6). There was mention that 'pop up' warning messages (online windows that appear in response to previously-identified illegal content, sometimes generated by the police) were not always perceived as helpful, "I always used to think that pop ups on screen were viruses so I used to click out of them and just not go to that thing" (PT2). Nevertheless, there was the suggestion of using link-pages on the Internet to advertise confidential help and to educate individuals that the images are abuse, not pornography, "A link which would bring you through to the testimony of someone who was a victim" (VT6) and "Re-labelling everything as child abuse images makes me feel like you've done wrong and it makes me think about, 'they are child abuse images, not child porn"” (VT4). This theme supports the notion that (at least this group of) CSEM offenders had engaged in attempts to self-manage their offending behaviour but mainly focused on increasing external inhibitions rather than internal inhibitions to offending behaviour.

\section{Thematic Synthesis and Model Development (Stage 5)}

Based on the theoretical framework and detailed analysis of these data, the emergent themes were integrated into a conceptual model of the aetiology of CSEM offending (Figure 2). The resulting model proposes three key areas of an individual's pathway to CSEM offending:

1) Offence-related Vulnerabilities, including developmentally determined factors, such as a sexual interest in children or socio-emotional dysfunctionality: 
2) the individual's Personal and Environmental Offence Context, such as a marriage breaking down or access to specific types of Internet applications

3) the immediate and longer-term Consequences.

Offence-related Vulnerabilities consist of both, an individual's motivational factors (resulting from the developmental context, such as a sexual interest in children) and facilitative internal states that decrease internal inhibitions to the offending behaviour, such as the endorsement of permission-giving thoughts. This distinction mirrors Seto's (2013) classification of facilitative and motivational personal factors. However, in the current model, we extended the definition of facilitative factors into those that are linked to the person (internal propensities, e.g., emotional detachment) and those that are linked to the environment (such as features of the Internet environment), reflecting Finkelhor's (1984) distinction of internal and external inhibitors of the offending behaviour. The participants' accounts highlighted that the online environment holds certain features, such as the relative ease of access to CSEM material, or the perceived anonymity/ invulnerability to detection and sanction, which can be facilitative in overcoming external inhibitions towards the offending behaviour. In addition, individuals may purposefully manipulate their offending context to decrease external inhibitions, such as the use of encryption software.

\section{Discussion}

The themes identified in the proposed model resonate with findings from the existing literature.

\section{Developmental Context, Personal Propensities, and Situational Factors}

CSEM offenders have been found to more frequently report adverse childhood events than control populations, such as physical and sexual abuse during childhood (Babchishin, Hanson \& Herrmann, 201; Webb et al., 2007); accounts of being bullied, or prolonged difficulties with peer relationships (Craissati, Webb, \& Keen, 2008); and difficult 
relationships with caregivers (Hanson \& Harris, 2000). Early sexualisation (possibly through use of pornography that becomes integrated into a coping repertoire, see, for example, Webb et al., 2007) is considered a trigger for later sexual interest in children (Babchishin et al., 2011; Sheehan \& Sullivan, 2010), and this might warrant further exploration for the relevance of CSEM offenders specifically. The participant's accounts of adverse sexual experiences and pornography use before and during adolescence reflected desensitisation to adult pornography (Quayle, Holland, Linehan, \& Taylor, 2000), but also potential psychosocial consequences of disrupted relationships (Wollert, Waggoner, \& Smith, 2009), leading to a decrease in self-esteem and low mood (Sheldon \& Howitt, 2007). The use of CSEM to address negative internal states (such as low self-esteem; McCarthy, 2010; a need for emotional closeness; Elliott, Beech, Mandeville-Norden, \& Hayes, 2009) as a dysfunctional coping strategy in response to negative life events (Quayle, Erooga, Wright, Taylor, \& Harbinson, 2006), including social withdrawal (Wollert et al., 2009) and substance use (Sheldon \& Howitt, 2007), is also well-established in the literature. While a sexual interest in children has been identified as a significant motivator for child sex offending (Mann et al., 2010), and is thus an offence-related risk factor, once carried out, a reinforcer of the offending behaviour, in the present study its role in offending pathways was only highlighted by a subgroup participants, which could be linked to issues with disclosure and/or highlight the heterogeneity of the functions linked to CSEM use (e.g., Seto et al., 2010).

\section{Permission-giving Thoughts and Sexual Arousal}

The cognitive conceptualisation of the offending context seems to play a critical role in the reported inhibitions towards offending behaviour. These cognitions can be both initiating and maintaining factors of the offending behaviour, and thus are developed and reinforced as a consequence of the offending behaviour. Participants' accounts of their permission-giving thoughts suggested that their content might be different to those of child 
sex offenders (e.g., Henry, Mandeville-Norden, Hayes, \& Egan, 2010; Merdian, Curtis, Thakker, Wilson, \& Boer, 2014), and a body of literature is emerging on this issue (Bartels \& Merdian, 2016; Howitt \& Sheldon, 2007; Kettleborough \& Merdian, 2017; O’Brien \& Webster, 2007).

However, permission-giving thoughts might be more or less active and/or accessible for the participant: In reviewing the literature and the participants' accounts, the interaction of sexual arousal and permission-giving thoughts became evident. Sexual arousal has been described as a state facilitator of sex offending behaviour (Pullman, Stephens, \& Seto, 2016), and for the participants was linked to both their offence motivation as well as gratification received from their CSEM offending. Although there is limited research on the arousal profiles of CSEM offenders, there is a body of research emerging on the impact of sexual arousal on decision-making in non-offending participants, which thus may interact with the prevalence of permission-giving thoughts (see Bartels, 2015). Research has shown sexually aroused males and females to be more likely to report an interest in unusual sexual behaviours (Ariely \& Loewenstein, 2006; Imhoff \& Schmidt, 2014; Loewenstein, Nagin, \& Paternoster, 1997) and for sexually aroused males and females to show greater willingness to

engage in other types of risky behaviours (e.g., gambling; Skakoon-Sparling \& Cramer, 2014; Skakoon-Sparling, Cramer, \& Shuper, 2016) and to make worse decisions during cybersex (Laier, Pawlikowski, \& Brand, 2014). Bouffard and Miller (2014) found that sexually aroused males were more likely to self-report sexually coercive behaviours and to overestimate a female's sexual interest. It is thus important to consider both, the role of sexual arousal as a stable factor (associated with sexual preferences) as well as short-term trigger to risky behaviour in the offence cycle.

\section{The Consequences for the Individual}


Findings emerging here are reflected in other CSEM research, such as the link to sexual gratification or the use of CSEM to escape reality (Quayle \& Taylor, 2005). This may maintain the CSEM offending behaviour if the consequence(s) were perceived as gratifying (in terms of positive or negative reinforcement; Wetterneck, Burgess, Short, Smith, \& Cervantes, 2012), regardless of whether the individual acknowledged that their behaviour was wrong (Taylor \& Quayle, 2006). Furthermore, the participants' accounts supported research suggesting an element of a loss of control linked to their Internet use (e.g., Davis, 2001). Participants described continuing their behaviour without thought for future consequences (Middleton et al., 2006) or the (negative) effects it had on their lives (such as decreases in social engagement; Taylor \& Quayle, 2003). Participants suggested that improvements in their personal circumstances (such as increased social connections, meaningful activities, being away from the computer) decreased CSEM offending behaviour, highlighting the importance of targeting personal factors in desistance planning.

\section{One-Sheet Formulation: Bringing it all Together.}

The current model, it is suggested, is a step towards the empirical exploration of exclusive CSEM offenders (fantasy-driven offenders) and to aligning them within the existing theoretical context. Participants' narratives, and consideration of the aetiological theories of contact sex offending applied to CSEM offenders, suggest that individual psychopathology alone does not account for the commission of CSEM offending. Instead, there is interaction between the individual's psychopathology and their proximal environment, which, when coupled with the Internet Environment, increases the risk of CSEM commission - and in some cases decreases engagement with the real world. The participants' narratives demonstrated the importance of considering these situational factors (i.e., the unique environment the Internet creates; Wortley \& Smallbone, 2006) within the aetiology of, and carrying out of, CSEM offending. These interacting factors, it is suggested, 
provide individuals presenting with offence-related vulnerabilities the opportunity to commit an online offence (Babchishin et al., 2015; Cohen \& Felson, 1979; Seto, 2013).

\section{Limitations}

At the time of data collection, participants were at different stages in the criminal justice system; the PT sample had received their conviction whereas the VT sample was often still awaiting their court dates. In Seto et al.'s (2010) study, the offenders' situations and the experience of the interviewers were found to be potential biases to the findings, which is likely reflected in the current study, especially with regards to the member of the interviewing team who worked for one of the recruitment locations at the time of data collection. In addition, interview situations varied between participants, in terms of length, content, and interviewer. A final issue was the length of the assessment, which may have caused a self-selection effect in the research (e.g., being prepared to take part in a lengthy process may be associated with factors such remorse and pro-social beliefs). Thus, it is vital for the resulting model to be validated on samples with wider representation.

Nevertheless, the study was intended to be wide-ranging in the information it elicited (from childhood through to current personal circumstances and offending behaviour) and multi-faceted in the themes it explored (attachments and relationships, sexual and social issues functioning) and was in many respects led by the participants' narratives of their offending pathways. Several participants commented that they had not previously made connections between some of these interacting influences on their lives, and on their pathway to offending behaviour.

\section{Conclusion and Future Directions}

This research developed a preliminary case formulation tool specific to CSEM offending, based on a set of interviews with acknowledged CSEM offenders and by utilising existing theory and empirical knowledge of CSEM offending. At this point, the model cannot 
be used as a risk-assessment tool. Rather, it is aimed at increasing understanding of an individual's unique pathway to their offending behaviour that is both comprehensive, concerning the establishment of functional links between past, present, and future behaviour, and between personal and situational factors, and collaborative, in that enquiry and analysis is shared with the individual client. Further research is needed to validate the identified themes and potentially link them with reoffending behaviour.

We hope that the resulting tool provides a useful framework for future research and presents an aid to practice-based case formulation of CSEM offenders. A key feature of the CSEM Pathways Model is that it is aimed to increase the individual's own understanding of their risks and treatment needs, and to develop their own solutions to relapse prevention, desistance, and social reintegration. Furthermore, the CSEM Pathways Model might also be a useful pre-assessment tool for standardised group intervention programmes, in order to highlight key target areas for each group members. 


\section{References}

Andrews, D. A., Bonta, J., \& Hoge, R. D. (1990). Classification for effective rehabilitation: Rediscovering psychology. Criminal Justice and Behavior, 17, 19-52. Doi: $10.1177 / 0093854890017001004$

Ariely, D., \& Loewenstein, G. (2006). The heat of the moment: The effect of sexual arousal on sexual decision making. Journal of Behavioural Decision Making, 19, 87-98. Doi: 10.1002/bdm.501

Babchishin, K. M., Hanson, R. K., \& Herrmann, C. A. (2011). The characteristics of online sex offenders: A meta-analysis. Sexual Abuse: A Journal of Research and Treatment, 23(1), 92-123. Doi: 10.1177/1079063210370708

Babchishin, K. M., Hanson, R. K., \& VanZuylen, H. (2015). Online child pornography offenders are different: A meta-analysis of the characteristics of online and offline sex offenders against children. Archives of Sexual Behaviour, 44(1), 1-22. Doi: $10.1007 / \mathrm{s} 10508-014-0270-\mathrm{x}$

Bartels, R. (2015, March 22). Does lust make us stupid? Part II. [Weblog post]. Retrieved from http://wp.me/p2RS15-98

Bartels, R. \& Merdian, H. L. (2016). The implicit theories of child sexual exploitation materials users: an initial conceptualization. Aggression and Violent Behavior, 26, 16-25. Doi: 10.1016/j.avb.2015.11.002

Boer, D. P., Hart, S. D., Kropp, P. R., \& Webster, C. D. (1997). Manual for the Sexual Violence Risk - 20: Professional guidelines for assessing risk of sexual violence. Vancouver, BC: The Mental Health, Law, and Policy Institute.

Bouffard, J. A. \& Miller, H. A. (2014). The role of sexual arousal and overperception of sexual intent within the decision to engage in sexual coercion. Journal of Interpersonal Violence, 29(11), 1967-1986. Doi: 10.1177/0886260513515950 
Braun, V., \& Clarke, V. (2006). Using thematic analysis in psychology. Qualitative research in psychology, 3(2), 77-101. Doi: 10.1191/1478088706qp063oa

Cohen, L. E., \& Felson, M. (1979). Social change and crime rate trends: A routine activity approach. American Sociological Review, 44, 588-608. Retrieved from:

http://www.personal.psu.edu/exs44/597b-Comm\%26Crime/Cohen_FelsonRoutine-

Activities.pdf

Cooper, A. (1998). Sexuality and the Internet: Surfing into the new millennium.

CyberPsychology and Behavior, 1(2), 187-193. Doi: 10.1089/cpb.1998.1.187.

Craissati, J., Webb, L., \& Keen, S. (2008). The relationship between developmental variables, personality disorder, and risk in sex offenders. Sexual Abuse: A Journal of Research and Treatment, 20(2), 119-138. Doi: 10.1177/1079063208317464

Crown Prosecution Service (2014). Violence against women and girls crime report 2013-14. Retrieved from http://www.cps.gov.uk/publications/docs/cps_vawg_report_2014.pdf

Davis, R. A. (2001). A cognitive-behavioural model of pathological Internet use. Computers in Human Behavior, 17(2), 187-195. Retrieved from www.elsevier.com/locate/comphumbeh

Elliott, I. A., Beech, A. R., Mandelville-Norden, R., \& Hayes, E. (2009). Psychological profiles of Internet sex offenders: Comparisons with contact sex offenders. Sexual Abuse: A Journal of Research and Treatment, 21(1), 76-92. Doi: 10.1177/1079063208326929

Finkelhor, D. (1984). Child sexual abuse: New theory and research. New York: Free Press.

Glasgow, D. (2010). The potential of digital evidence to contribute to risk assessment of Internet offenders. Journal of Sexual Aggression, 16(1), 87-106. Doi: $10.1080 / 13552600903428839$ 
Hanson, R. K. \& Harris, A. J. R. (2000). Where should we intervene? Dynamic predictors of sexual offense recidivism. Criminal Justice and Behavior, 27(1), 6-35. Doi:

$10.1177 / 0093854800027001002$

Henry, O., Mandeville-Norden, R., Hayes, E., \& Egan, V. (2010). Do Internet-based sex offenders reduce to normal, inadequate and deviant groups? Journal of Sexual Aggression, 16(1), 33-46. Doi: 10.1080/13552600903454132

Howitt, D. \& Sheldon, K. (2007). The role of cognitive distortions in paedophilic offending: Internet and contact offenders compared. Psychology, Crime and Law, 13(5), 469-486. doi: $10.1080 / 10683160601060564$

Imhoff, R., \& Schmidt, A. F. (2014). Sexual disinhibition under sexual arousal: Evidence for domain specificity in men and women. Archives of Sexual Behavior, 43, 1123-1136. Doi: $10.1007 / \mathrm{s} 10508-014-0329-8$

Kettleborough, D. \& Merdian, H. L. (2017). Gateway to offending behaviour: permissiongiving thoughts of online users of child sexual exploitation material. Journal of Sexual Aggression, 23(1), 19-32. Doi: 10.1080/13552600.2016.1231852

Laier, C., Pawlikowski, M., \& Brand, M. (2014). Sexual picture processing interferes with decision-making under ambiguity. Archives of Sexual Behavior, 43(3), 473-482. Doi: $10.1007 / \mathrm{s} 10508-013-0119-8$

Loewenstein, G., Nagin, D., \& Paternoster, R. (1997). The effect of sexual arousal on expectations of sexual forcefulness. Journal of Research in Crime and Delinquency, 34(4), 443-473. Retrieved from http://www.cmu.edu/dietrich/sds/docs/loewenstein/EffectSexualArousalForcefulness.pdf

Mann, R., Hanson, R. K., \& Thornton, D. (2010). Assessing risk for sexual recidivism: Some proposals on the nature of psychologically meaningful risk factors. Sexual Abuse: A Journal of Research and Treatment, 22(2), 191-217. Doi: 10.1177/1079063210366039 
McCarthy, J. A. (2010). Internet sexual activity: A comparison between contact and noncontact child pornography offenders. Journal of Sexual Aggression, 16(2), 181-195. Doi: $10.1080 / 13552601003760006$

Mercado, C. C. \& Ogloff, J. R. P. (2007). Risk and the preventive detention of sex offenders in Australia and the United States. International Journal of Law and Psychiatry, 30(1), 49-59. doi: 10.1016/j.ijlp.2006.02.001

Merdian, H. L., Curtis, C., Thakker, J., Wilson, N., \& Boer, D. (2014). The endorsement of cognitive distortions: comparing child pornography offenders and contact sex offenders. Psychology, Crime \& Law, 20(10), 971-993. Doi: 10.1080/1068316X.2014.902454

Merdian, H. L., Moghaddam, N., Boer, D. P., Wilson, N., Thakker, J., Curtis, C., \& Dawson, D. (2016). Fantasy-driven versus contact-driven users of child sexual exploitation material: offender classification and implications for their risk assessment. Sexual Abuse: A Journal of Research and Treatment. Published online before print. Doi: $10.1177 / 1079063216641109$

Middleton, D., Elliott, I. A., Mandelville-Norden, R., \& Beech, A. R. (2006). An investigation into the applicability of the Ward and Siegert Pathways Model of child sexual abuse on Internet offenders. Psychology, Crime and Law, 12(6), 589-603. Doi: $10.1080 / 10683160600558352$

Middleton, D., Mandelville-Norden, R., \& Hayes, E. (2009). Does treatment work with Internet sex offenders? Emerging findings from the Internet Sex Offender Treatment Programme (i-SOTP). Journal of Sexual Aggression, 15(1), 5-19. Doi: $10.1080 / 13552600802673444$

O'Brien, M. D. \& Webster, S. D. (2007). The construction and preliminary validation of the Internet Behaviours and Attitudes Questionnaire (IBAQ). Sexual Abuse: A Journal of Research and Treatment, 19(3), 237-256. doi: 10.1007/s11194-007-9057-0 
Prochaska, J. O. \& Norcross, J. C. (2007). Systems of Psychotherapy: A transtheoretical analysis (6th ed.). Belmont, CA: Thomson Brooks/Cole.

Pullman, L., Stephens, S., \& Seto, M. C. (2016). A motivation-facilitation model of adult male sexual offending. In C. A. Cuevas \& C. M. Rennison (Eds.), Handbook on the Psychology of Violence (pp. 482-500). Hoboken, NJ: John Wiley \& Sons.

Quayle, E., \& Taylor, M. (2005). Viewing child pornography on the internet: Understanding the offence, managing the offender, helping the victims. Lyme Regis: Russell House Publishing.

Quayle, E., Erooga, M., Wright, L., Taylor, M., \& Harbinson, D. (2006). Only pictures? Therapeutic work with Internet sex offenders. Dorset, UK: Russell House Publishing.

Quayle, E., Holland, G., Linehan, C., \& Taylor, M. (2000). The Internet and offending behaviour: A case study. Journal of Sexual Aggression, 6, 78-96.

Seto, M. C. (2013). Internet sex offenders. Washington, DC: American Psychological Association.

Seto, M. C., Cantor, J. M., \& Blanchard, R. (2006). Child pornography offenses are a valid diagnostic indicator of paedophilia. Journal of Abnormal Psychology, 115(3), 610-615. Doi: 10.1037/0021-843X.115.3.610

Seto, M., \& Eke, A. (2015). Predicting recidivism among adult male child pornography offenders: Development of the Child Pornography Offender Risk Tool (CPORT). Law and Human Behaviour, 39(4), 416-29. Doi: 10.1037/lhb0000128.

Seto, M. C., Reeves, L., \& Jung, S. (2010). Explanations given by child pornography offenders for their crimes. Journal of Sexual Aggression, 16(2), 169-180. Doi: $10.1080 / 13552600903572396$ 
Sheehan, V. \& Sullivan, J. (2010). A qualitative analysis of child sex offenders involved in the manufacture of indecent images of children. Journal of Sexual Aggression, 16(2), 143167. Doi: $10.1080 / 13552601003698644$

Sheldon, K., \& Howitt, D. (2007). Sex offenders and the Internet. Chichester, UK: West Sussex.

Skakoon-Sparling, S., \& Cramer, K. (2014). Paratelic/ telic state, sexual arousal, and sexual risk-taking in university students. Journal of Motivation, Emotion, and Personality, 2, 32 37. Doi: 10.12689/jmep.2014.204

Skakoon-Sparling, S., Cramer, K., \& Shuper, P. A. (2016). The impact of sexual arousal on sexual risk-taking and decision-making in men and women. Archives of Sexual Behavior, 5(1), 33-42. Doi: 10.1007/s10508-015-0589-y

Taylor, M., \& Quayle, E. (2003). Child pornography: An Internet crime. Hove, UK: BrunnerRoutledge.

Taylor, M. \& Quayle, E. (2006). The Internet and abuse images of children: Search, precriminal situations and opportunity. In R. Wortley \& S. Smallbone (Eds.), Crime Prevention Studies Vol. 19: Situational prevention of child sexual abuse (pp. 169-195). Devon, UK: Willan Publishing and Criminal Justice Press.

Taylor, M. \& Quayle, E. (2008). Criminogenic qualities of the Internet in the collection and distribution of abuse images of children. The Irish Journal of Psychology, 29(1-2), 119130.

Wakeling, H. C., Howard, P., \& Barnett, G. (2011). Comparing the validity of the RM2000 Scales and OGRS3 for predicting recidivism by Internet sex offenders. Sexual Abuse: A Journal of Research and Treatment, 23(1), 146-168. Doi: 10.1177/1079063210375974 
Webb, L., Craissati, J., \& Keen, S. (2007). Characteristics of Internet child pornography offenders: A comparison with child molesters. Sexual Abuse: A Journal of Research and Treatment, 19(4), 449-465. Doi: 10.1007/s11194-007-9063-2

Wetterneck, C. T., Burgess, A. J., Short, M. B., Smith, A. H., \& Cervantes, M. E. (2012). The role of sexual compulsivity, impulsivity, and experiential avoidance in Internet pornography use. Psychological Record, 62(1), 3-18.

Wollert, R. W., Waggoner, J., \& Smith, J. (2009, October). Child pornography offenders do not have florid offense histories and are unlikely to recidivate. Poster presented at the 28th Annual Conference of the Association for the Treatment of Sexual Abusers, Dallas, Texas.

Wortley, R. K., \& Smallbone, S. (2006). Applying situational principles to sexual offending against children. In R. K. Wortley \& S. Smallbone (Eds.). Situational prevention of child sexual abuse (pp. 7-36). Morsey, NY: Criminal Justice Press. 
Figures 


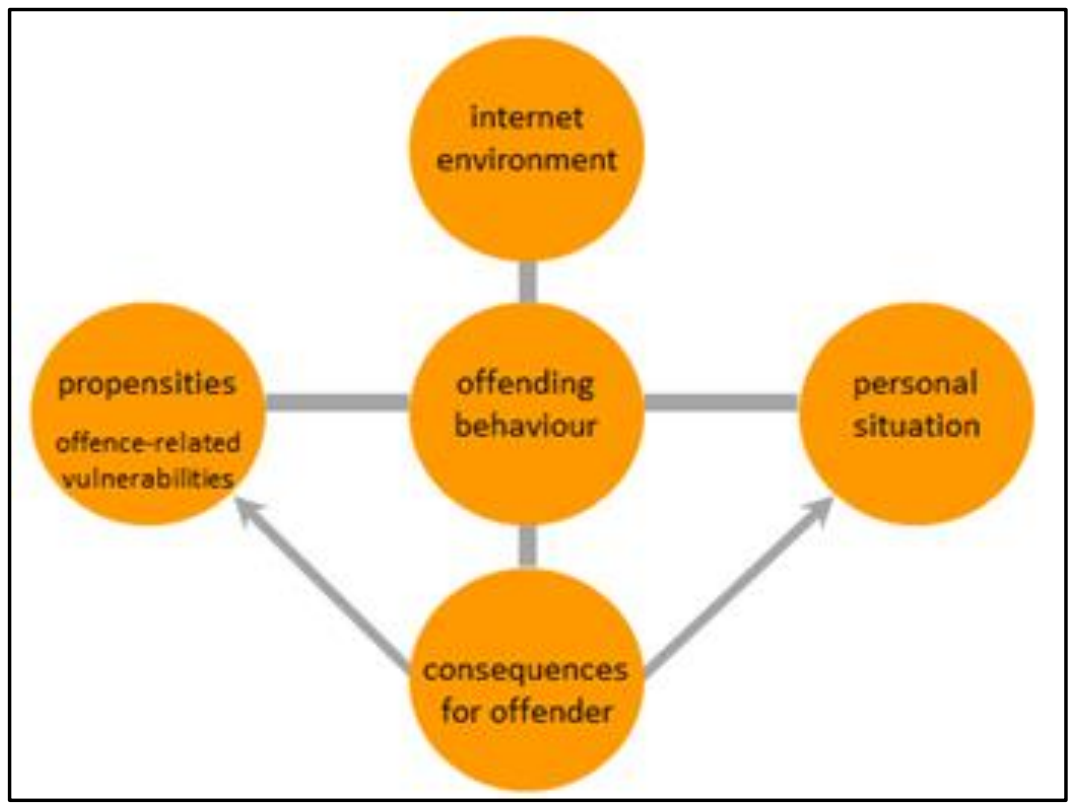

Figure 1: Interim Aetiological Model of Pathways to CSEM Offending 


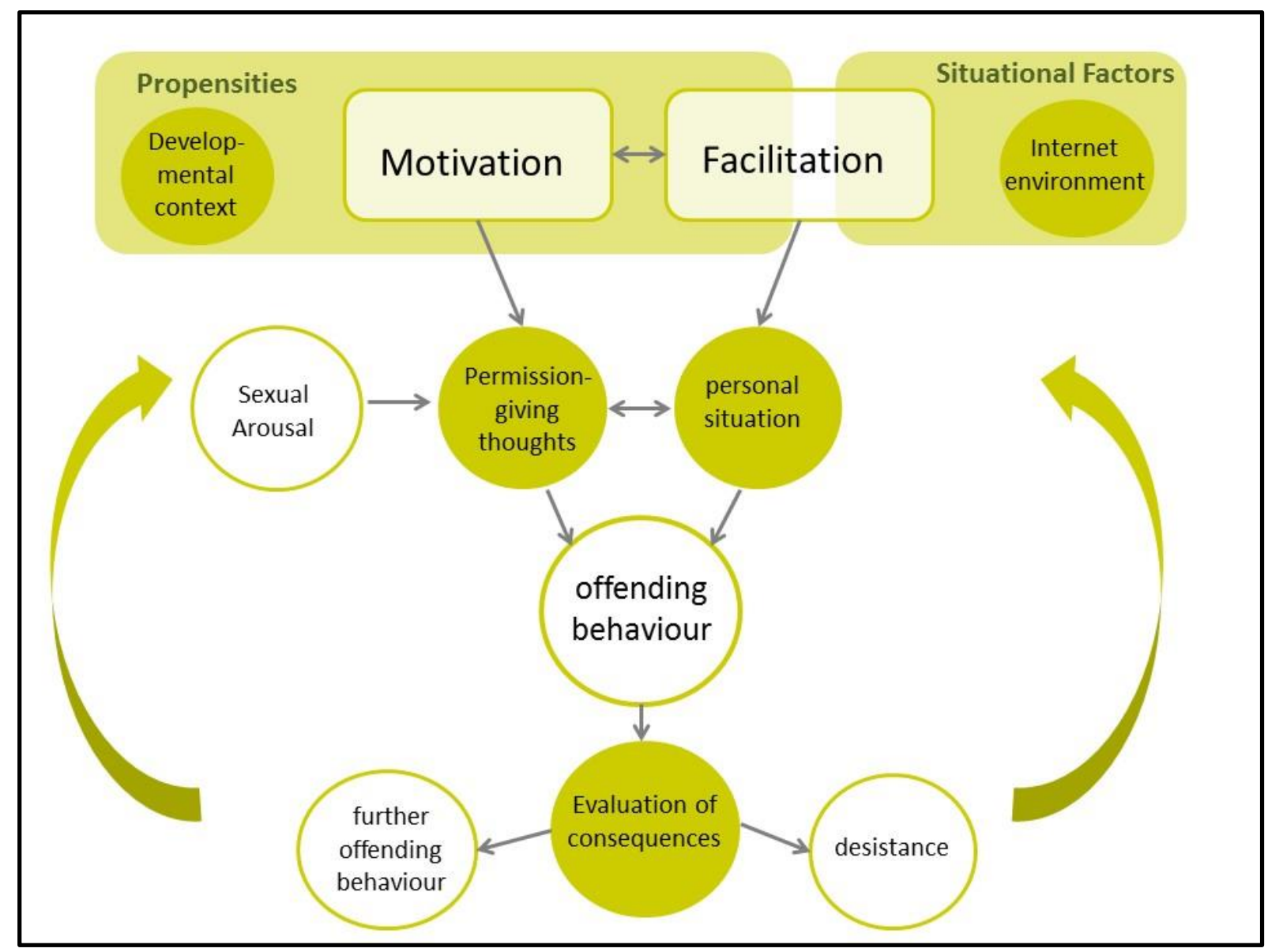

Figure 2: Case Formulation Model of Pathways to CSEM Offending

Note. CSEM = child sexual exploitation material 


\section{Author Page}

Hannah L. Merdian, PhD, School of Psychology, University of Lincoln, School of Psychology, Brayford Warf East, LN5 7AY, Lincoln, UK; Derek E. Perkins, PhD, School of Law, Royal Holloway, University of London, Egham, Surrey, TW20 0EX; Elspeth Dustagheer, MSc Forensic Psychology, School of Psychology, University of Surrey, AD Building, Guildford, GU2 7XH, UK; Emily Glorney, PhD, School of Law, Royal Holloway, University of London, Egham, Surrey, TW20 0EX, UK.

Elspeth Dustagheer is now at the School of Medicine, Division of Psychiatry and Applied Psychology, University of Nottingham, Yang Fujia Building, Jubilee Campus, Nottingham, NG8 1BB, UK. Email: msxed3@nottingham.ac.uk

Correspondence concerning this article should be addressed to Hannah Merdian, University of Lincoln, School of Psychology, Brayford Warf East, LN5 7AY, Lincoln, UK. Email: hmerdian@lincoln.ac.uk

' Forums included: a research steering group meeting at West Mercia Police (UK), June 2013; a workshop at the Conference of the National Organisation for the Treatment of Abusers, Cardiff (Wales), September 2013; a research seminar at the University of Lincoln (UK), November 2013; a presentation and discussion at the Conference of the European Association of Psychology and Law, St Petersburg (Russia), June 2014; and at the Sex Offending Research and Practice Conference at the University of Lincoln (UK), April 2015. 